Sectional and Vicrascopic Appearances. A section in the longest axis of the organ showed two distinct appearances, namely, a part of a dense gristly hardness, and a part which evidently corresponded to the medullary part of the organ, which was chiefly occupied by a yellow deposit. In the medullary portion of the organs, the morbid process appeared to have adranced the most, and to be in the greatest abundance. Deposition and subsequent softening of exuded matter of a marked and peculiar aspect, resembling very much what is usually called scrofulous, tubercular, or yellow cheesy-like matter, occupied the medullary portion of the capsule. The veins from the organ were generally diminished in size, and the cavity corresponding to the central renous sinus was entirely occupied by the yellow exudation, in various conditions as to softening. Small sacs of various sizes were scattered throughout the stroma (cortical) of the organ, and contained the same scrofulous looking material, in various states of consistence. No true oval resicles natural to the cortical substance of the viscus could be seen by the microscope; and the only structure of an elementary form, which could be observed and referred to the normal histological elements of the suprarenal body, consisted in the caudate and branched nucleated cells seen in the firmer parts of the yellow deposit, which involved the medullary portion of the organ. The gristly hard part was composed, microscopically, of fibrinous elements, in the form of elongated, fusiform, and spindle-shaped cells, with simple and compound nuclei, together with fine filamentous fibres and granular matter. The yellow matter was made up of fine granular stroma, in which compound granular corpuscles, oil granules, and globules, together with crystals soluble in acetic acid, were most obvious and abundant. Clear and transparent cells, free of nuclei, together with club shaped, caudate, and very irregularly branched cells, with simple and compound nuclei, were also obvious constituents. The nucous membrane of the mouth was thin, pale, and bloodless, the labial and buccal- glands shining prominently through. The stomach and substance of the intestinal tube were uniformly thin throughout. In the stomach, the solitary gastric glands were remarkably prominent, while the mucous membrane generally was wasted and atrophic. Microscopic sections from the jejunum and ileum showed the villi remarkably attenuated, and the mucous membrane very readily separated from the adjacent muscular part of the gut. The tubular glands of the mucous membrane were almost entirely gone, and their place was supplied by a granular amorphous material. The average specific gravity of the mucous membrane was 1,040 .

Rexarks. Any speculation as to the cause of the colour of the skin in this singular disease, and especially its relation to the morbid condition of the suprarenal capsules, would at the present time be entirely out of place. The plain duty of practical physicians, for the present, seems to be to observe and put on record cases which may occur in their practice; and when these have accumulated in sufficient numbers, and the various facts and circumstances attending them have been thoroughly investigated and compared, something of a more definite and satisfactory opinion may be formed of the nature and character of the disease.

The greatly increased size and rosy hue of the nerves in contact with and passing into the morbid organs are worthy of notice; but whether these appearances were the result of an inflammatory condition of the capsules, or not, it would be unsafe to hazard an opinion. From all the appearances attending the case, the tubercular depositions at the apices of both lungs, and the scrofulous cheesy-like matter occupying the medullary portion of the capsules, I am inclined rather to view this disease as belonging to the class tuberculosis than to that of phlegmasia, and, in the meantime, to be treated by every means which tend to invigorate and strengthen the system, and more especially by the use of cod-liver oil.

\section{ON FACAL FERMENTATION AS A SOURCE OF} DISEASE.

By C. H. F. Routr, M.D., Physician to the St. Pancras Royal. General Dispensary; Assistant.Physician to the Samaritan Hospital for Women and Children; Vice-President of the Medical Society of London; etc.

[Read before the Medical Society of Iondon, May 17th, 1056.]

\section{Part IV.}

RULES OF TREATMENT TO BE ADOPTED.

If the views which I have enunciated are correct, and the development of the diseases mentioned, whether communicated by fæcal matter in substance, in solution in water, or through a moist atmosphere, is due to a process of fermentation which generates the poison, it is clear that the remedies to be adopted are those which arrest fermentation, or, at any rate, those which, if they do not exactly arrest it, either absorb or modify the character of the poisonous sporules or gases formed during the process of fermentation, and so impede their action. We have, moreover, to consider the treatment in two points of view.

First, in its curative effect, as relating to an individual already affected.

Secondly, in its prophylatic effect, as relating to communities, to prevent their being affected. Both points of view have the closest relation, although they are best separately considered.

1. Curative Effect of Treatment. The remedies here applicable are those called antiseptics; and they consist of all those substances which chemically act on the ferments, because they have an affinity for them, and thus bring about an equilibrium in the fermenting body. "Among these we may enumerate alkalies, mineral acids, concentrated vetetable acids, rolatile oils, alcohol, sea salt (in excess). The most effective is sulphurous acid, the metallic salts, especially those of mercury. Arsenious acid does not prevent the putrefaction of blood, nor the ordinary alcoholic fermentation of sugar, but entirely suppresses the putrefaction of the skin and gelatinous tissues." (Liebig's Letters on Chemistry.) Chlorine retards putrefaction, as before stated, by forming with dead animal matter a white pearly compound, which is almost imputrescible; phosphorus and deutoxide of hydrogen, by absorbing oxygen ; creasote and ammonia also retard putrefaction, as before noted. We may also get a practical lesson from the processes employed for the disinfection of manures, which at least prevent the generation of emanations from them, if they do not completely arrest fermentation. "The disinfection of manure has for its object to destroy the offensive odour, and to cause the phosphates to be retained in a form capable of being assimilated by the plants" (Liebig and Kopp's Report, p. 439, 1850); and a great variety of processes have been adopted. One of these has for its object the formation of charcoal, which may be procured largely in several ways. The slime and mud of the Seine in Paris, as also of the Thames, contains very much animal and vegetable matter intermixed with it, which, if burnt, constitutes a very efficient kind of charcoal for this purpose. This is Mr. Salmon's method. Mr. Alfred Samson found that the cinders of peat or turf, or the simple refuse of carbonised peat, had the same effect. The bran obtained from sawing wood, the refuse of oak which has been used for tanning leather, the mould on the Parisian strata, answer the same purpose; and, when fæcal matters are mixed with simple clay, it is only necessary to carbonise this admixture, and we obtain at once a perfect disinfecting powder. Hydrochloric acid is also said to act as a powerful disinfectant, by fixing the ammonia. The tribasic phosphate of soda has also been praised as a disinfectant. Calrond, in his Journal de l'harmacie, quoted by Liebig and Kopp (Op. cit. and Journal de Pharmacie, svii, p. 281), finds that the methods usually employed do not fully satisfy any of the conditions required, but that the mother liquor of salt-works can be used with great advantage, and most perfectly, for disinfection. 
It is impossible to look orer this list of antiseptics and pirinfectents without being struck with the fact, that among them are to be found most of those remedies which we have been in the habit of hearing 80 vaunted in practice for the cure of the diseases spoken of in this paper. I will instance a few of these: sulphuric acid, a mineral acid, found to be most useful in cholers; also cajuput, an essential oil, in the first epidemic in this country; chalk, an alkaline earth, in the premonitory and other diarrhoeas; saline injections; commion salt, and its internal administration in large quantities, as in the case of the late Mr. Carmichael of Dublin ; mercury, according to Dr. Ayre's plan; and lastly, charcoal, which proved so invaluable a remedy among the choleraic patients in Canada in 1832. The disease was then at its height, when a stranger made his appearance in the colony, and administered charcoal largely; and the result was, that cures were very frequent, and tho epidemic soon disappeared. The effect was so marked, that this stranger was believed by the ignorant to be a saint, having succeeded where the doctors failed. I have also been told that phosphorus proved in many cases, in the hands of a London practitioner, a most efficacious remedy. Dysentery is another disease in which antiseptic remedies have been given with success, such as sulphate of copper and alum, metallic salts; not to speak of small doses of calomel, another metallic salt, opium and carhonate of soda: the last an alkali. Charcoal has also been found most efficacious in dysenteries and diarrhcoas, especially when complicated with intermittent ferer. It is known in Smyrna to exert sometimes a curative effect in intermittent fevers, where quinine has failed; and this fact is confirmed by the experience of the learned Dr. Calvert, Calsagno, Macadino, Morsia of Nissoria, Burza of Palermo, Borland, and Tully. (See Edinburgh Medical and Surgical Journal, vol. x.) Perhaps, indeed, bark itself acts as an antiseptic. From some experiments made by Dr. M'Bride, it would appear that, if putrefaction has not proceeded to a very great degree, it may be arrested by infusion of bark. Thus, Dr.

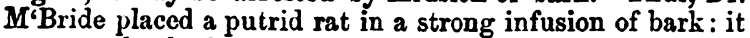
was completely deodorised thereby. If the putridity, however, was far adranced, the infusion failed. Certainly the change effected in many low fevers by bark is well ex. plained on this view. Pariset belicres that the reason that the plague does not produce a greater mortality in Egypt is, that the Nile water is very alkaline, and that spreading, in the annual inundations, over the country, it neutralises the miasmata. Most of the remedies I have mentioned have been employed in fever, and each could no doubt find some adrocate in this Society. Charcoal is less often giren in fever in this country than it might be. I am satisfied that, in my hands, it has been a means, under Providence, of saving life in cases of fever, particularly when these have been accompanied with very offensive stools, and in the remittent ferer of infants.

It would be useless in me, however, to extend on this point. If the diseases in question be induced by fermentation, and especially in those cases where that fermentation is of frcal origin, the remedies which common sense would indicate are those which arrest this action, namely, antiseptics and disinfectants. This, it appears to me, is the only philosophical treatment, and so far it is that which theory and practice alike support. Till, howerer, we know more of the peculiar chemical nature of each poison, we must, when once the broad principle is laid down, prosecute by empirical experiment. It may be, and it no doubt is so, that there is a specific antiseptic for every disease of the kind specified, and for many more. Sulphuric acid may be the best in cholera; mercury or wine in fever, as the case may be: furthermore, each may be susceptible of a similar explanation to that given for arsenic, which may be supposed to prove sometimes the best remedy for skin-disease, because it specifically arrests fermentation in the skin. But, at any rate, the remedies to be sought for are, theoretically, to be found among those which, by arresting fermentation in the system, prevent its extension.
While I atate this, however, I must guand myself from an inference which may be made. I do not wy that all ferers, or eren the diseases here mentioned as fermentative, may not be cured by remedies which act otherwise than as antiseptics. This is quite possible, and I am bound to admit it. I merely suggest one mode in which many remedies may act.

2. Prophylactic Effect of Treatment. The treatment must be prophylactic, as well as curative. In a sanitary point of view, the remedies used must not only aim to cure the local malady in the patient's body, but to prevent its diffusion through a town, or wherever a number of individuals are congregated together. Now, as means to this end, our attention has of late been directed to two agents, both of which have been recommended-charcoal and fresh sea water.

(a) Charcoal. I have before spoken of charcoal as an antiseptic, although, from Dr. Stenhouse's inquiries, it appears to be a deodoriser from an opposite property, by reason of the large quantity of oxygen contained in its pores, which it absorbs, together with the miasmata and bad smells of decaying substances. These last are rapidly burnt and destroyed; so that, in point of fact, charcoal is not purely an antiseptic, but a destructive of decaying matters. A series of very valuable papers have been contributed, on this subject, to the Journal of Public Health, which have fully brought out the advantages of this agent as a disinfectant and purifier. Dr. Stenhouse's plan of air-filters, applied over offensive gulley-holes, would go far towards removing the foul odours of our London streets; and a similar kind of. apparatus, to cover the apertures of water-closets in private houses, but especially in hospitals, would very much increase the comforts of their residents. In like manner, if bodies were buried in charcoal, according to Dr. Richardson's-suggestion, all odour from this source would be removed, and not conveyed by solution, after sharp rains, within the common sewers. But this will not suffice. The sewers themselres will continue to emit these odours. All gulley-holes cannot be closed by charcoal airfilters, and the mud and rain must pass downwards into them through some openings ; and it is therefore necessary, if possible, that something should be devised to deodorise the common sowers themselves. The employment of hydrochloric acid, chloride of lime, and pure charcoal, would involve too much expense-the first two in particular. In a very able paper by Mr. Durden in the Journal of Public Health (vol. i, p. 213), on the Preparation of Charcoal, the preferable mode, because the cheapest, would seem to be by the action of sulphuric acid on sawdust. The chief objection, however, to this plan, is the great uncertainty of procuring the raw material, the sawdust, in sufficient quantity-a difficulty on which many a city company, whose profits, as set forth in their prospectuses, were to have been extraordinarily great, has foundered. But I think that we need only follow out in London Mr. Salmon's plan, already adopted so successfully in Paris. Assuredly, old Father Thames contains animal and vegetable matter in greater abundance than the Seine in its slime and mud; and since, when this is burnt, it yields a charcoal in a very fine state of powder, and which possesses the disinfecting property to an extraordinary degree, we have at our doors a source whence charcoal can be obtained in abundance and of excellent quality, and whence it could be very cheaply collected and prepared.

If once obtained in sufficient quantity, nothing could be easier than its transmission, by suspension in water, into the common sewers, from certain high localities before selected and established. We should do what we are now doing when we flush the sewers, only we should deodorise at the same time, instead of forcing upwards through the pipes of water-closets, and all the gulley-holes in town, those pestilential odours which are so fearfully obnoxious, and which originate or aggravate disease.

I am not aware that any but one objection of weight has been made to this introduction of charcoal, and it is that in course of time the sewers would become clogged up, and 
in this manner the flow through them arrested. I bolieve that this supposed effect is greatly exaggerated. The fine mud and broken up frecal matters have not usually this effect. And if the supply of water passed through the drains at the same time be great, so that the current in the sewers is increased, and the size of the sewers be sufficient, I think no such effect would follow. Indeed, if obstruction did occur, perhaps in the end it would prove of advantage, because it would compel builders and the parochial authorities to repair and widen the narrow and faulty sewers, and to build any new sewers required upon an improved and more scientific plan.

(b) Water. I now come to the next point, the supply of water required for the suspension and diffusion of this deodorising powder. Under this plan, impure water would offer no impediment. The most offensive and impure water loses all odour by admixture with charcoal. All that would be needed would be a large reservoir with a smooth bottom, from which the water, mixed gradually with charcoal and agitated by machinery (such, for instance, as a paddle wheel) could be emptied in quantity and at fixed intervals into the sewers. The foulest Thames water, or the Serpentine water of the parks, would suffice. I think this supply would be found sufficient; so that there would be no need to bring sea water into London according to Mr. Fuller's plan, which I believe is upon the whole rery objectionable, at least so far as relates to the watering of the streets by it. From the facts before recorded on the subject of sea water, putrefaction and foul odours would be augmented, at least in the hot weather. I mas add a few additional facts on this point. In a high temperature, at least so far as my experiments go (I speak of a temperature above $60^{\circ}$ ), animal matters will putrefy more rcadily and quickly in sea water than in fresh water. I have often noticed this result in vivaria. If a snail or a fish died in a fresh voater vivarium, it might remain in the basin three or four days and longer, and the water did not sensibly suffer; the remaining animals escaped with impunity. In the marine vivarium, if a periwinkle or anemone died, in two or three days the water smelt strongly, and the remaining animals all died. This result I have frequently noticed in the same conservatory, where both vivaria were exposed to the same influences. I have also noticed a fact which, so far as chloride of sodium is concerned, seems to prove that a small quantity of this salt rather favours decomposition. I was preparing some of Liebig's beef tea: the temperature was tepid, and it was apparently fit to drink. In this state I thought to make it more palatable by the addition of a small quantity of salt. I added this, and the result was that it suddenly frothed up, and became very offensive ; putrefaction had begun. Matters to be kept must be highly salted, and the temperature must be low, otherwise they will putrefy as readily, if not more so, than if not salted. In the instance of the Bermuda fever, to which I alluded before in my last paper, I instanced the case of the mud in which the convict hulk the "Thames" was fixed; although the water orer it during the tidal rise was changed twice daily, the odour was very powerful from decomposing animal, especially fæcal, and vegetable matters. Sea weed will readily putrefy under a hot sun, though saturated with sea water. I therefore cannot help thinking that the beneficial effects of sea water have been overrated. Still I think that, if undiluted with much water, it does not in itself favour the extension of some epidemic influences. As a rule, watering places, and particularly those where there is no fresh water river at hand, are healthiest; and except where cases are continually imported, or where bad water is drunk, epidemics, such as cholera, for instance, are not propagated. The coexistence, howerer, of a river, by the admixture of the waters of which the sea is unduly diluted, more especially if offensive sewage forms any part of this admixture, has quite an opposite effect. In such localities, some epidemics when present rapidly extend, and are very hatal. I see, then, no good result likely to be obtained by the substitution of ea for fresh water for the purpose of watering the streets.
I have said that the most impure fresh water would become purified and deodorised by the charcoal admixture. But the adoption of this plan should not be limited to the common sewers. There are $t w o$ sources of infection without the sewers to which the deodorising measure should be applied. 1. The ordinary water-closets in demiciles should from time to time have charcoal thrown down into them; and whatever is inconsistent with its transmission, such as syphon. or old fashioned traps, removed. If this were done, the source of annoyance in our houses from these odours would be removed. 2. We all know to our cost how offensive are mews, particularly in summer; and as before stated, during the late epidemic of cholera, it was the inhabitants of these localities who suffered most. If, in these, alternate layers of charcoal and stable refuse were interposed, the odour would in great measure disappear. I am aware, however, that John Bull could only be compelled to do this by an act of Parliament.

In any general plan, however, which should be adopted, it is expedient that the sewage matter now deodorised should be direrted from the Thames and carried out of town. But $I$ think it is one of the adrantages accruing from the employment of charcoal, that, once deodorised, there is no need of conveying it to such great distances from London. A distant removal has its adrantages as affording larger space for operations, but then the tunnelling of the main sewers to such a locality is peculiarly expensive. If the deodorising process be effected in the sewers, a Montfaucon in London, even as near as that in Paris, would cease to be so great a nuisance; and the air being no longer tainted by vile odours, and not capable of being wafted back on the town, all disadvantages of proximity would cease. How near this proximity should be is then, after all, resolved into a matter of convenience to the public.

To agriculturists, the advantage of such a ready made manure at the very doors of every large town would be infinite. Human manure is inferior to none, and equal to guano, and could be procured at a price considerably less. To the inhabitants of tovons, a comparatively pure atmosphere, a less frequent recurrence of pestilence, and a more benignant type of disease would, under God's blessing, be the well earned reward.

\section{ILLUSTRATIONS OF THE PATHOLOGY OF CANCER.}

By J. Zacharia Latresce, Esq., F.R.C.S.

\section{PART III.}

TIE RELATION OF CANCER TO TUBERCLE.

H $\triangle$ YYOVER states that, in 338 post mortem examinations in the Friedrich's Hospital in Copenhagen, cancer was found combined with tubercle only three times. In 104 necropsies of cancer, Walshe observed only seven instances of tubercle. Paget gires a well marked case. Lebert relates an interesting illustration. A woman, aged 62 years, died with all the symptoms of advanced phthisis. At the autopsy, crude and softened tubercles and vomicr were found in the apices of the lungs; the peritoneum contaiued many partly cancerous, partly tuberculous infiltrations. The liver also contained cancerous masses, mingled with deposits of tubercle. Dr. Carl Martius of Erlangen has accurately recorded twelve necropsies of tuberculosis of the lungs, combined with cancer in other organs of the body. ${ }^{*}$ Up to the time of publication of my essay on Cancer, I had observed two cases of the coexistence of cancer and tubercle; neither of these cases were, however, very satisfactory ones; one was carcinoms of the right auricle of the heart-a dissectionroom case; the second a case of colloid (on the nature of which disease opinions are still divided) of the peritoneum. In both of these genuine crude tubercles were found in

Die Combinationsverhälnisse des Krebses und-der Tuberculose, von Dr. Carl Martius. Erlangen: 1853. 